no indication (except the external marks) of the former long continued disease.

The young man was employed in cultivating the ground attached to the union house for several months after he was cured; and has since been employed regularly as an agricultural labourer at a farm-house, and enjoys excellent health.

\section{THE CALABAR BEAN PAPER, AND ITS EFFECTS UPON THE PUPIL OF THE EYE.}

By John W. Ogle, M.D., F.R.C.P.

IN the number of this JoJrnal for the week before last, I made some remarks upon the action of the Calabar bean on the pupil. I there stated that I had had a "paper" prepared by saturation with a solution of the bean, analogous to that which, at Mr. Streatfeild's request, was made with a soiution of atropine; but that I had not yet been able to use it. Owing to several inquiries having been made about the matter, and to the fact that $M r_{\text {. }}$ Squire had placed in my hands a portion of Calabarbean "paper", I have since then conducted some observations which show that the Calabar bean paper is equally useful and aetive, and equally commodious, in another direction, with the atropine paper to which I alluded.

I subjoin the following experiments, which, perhaps, will suffice to confirm what I have remarked.

Experiment I. In the case of a young woman, in whom the right pupil was about one-fourth larger than the left one, I inserted a portion of the Calabar bean paper between the lower eyelid and the eyeball at 12.20 P.M., and left it there. The patient reappeared at 12.30 ; and the pupil of the right eye was reduced to the size of a pin's head, being about one-fourth of the size of the left one.

EXPERIment Ir. In another case in which the pupil of the right eye was of larger size than its fellow, $I$ in serted the Calabar bean paper (as before) at 1.6 P.M. At 1.13, the pupil was beginning to contract. At 1.20, the pupil of the right eye was decidediy less in size than that of the opposite one; and at 1.27, it was of the size of a pin's head.

EXPeniment IIr. At 1.55 P.M. I inserted the Calabarbean paper as before. At 2.6, the pupil was decidedly smaller than its fellow. At 2.10, it was much smaller; and at 2.15, it was of about the size of a pin's head.

Experiment Iv. In the case of a patient whose pupils were equal, at 1.55 P.Mr. I inserted a portion of the Calabar bean paper as before. At 2.6, the pupil of the eye was decidedly smaller than the opposite one. At 2.10 , it was much smaller; and at 2.15 , it was perfectly contracted.

EXPERIMENT v. In this case of a man whose pupils were equal, of ordinary size, and acting well under light, I inserted a portion of the "paper" at 12.44 P.M.; and at 1.20, when the man returned to me, the pupil of the eye to which I had applied it was reduced to the size of a pin's head.

I have not had the opportunity of ascertaining how long the contraction of the pupils continued in these cases.

It is quite clear, I think, that the Calabar bean paper will answer well as a contractor of the pupil. The task which remains in using the Calabar bean and the atropine papers as antagonisers is, to regulate the strength of the respective solutions of which these "papers" are made.*

* In two of the above cases, but in one especially, I noted a peculiar movement of the iris of both eyes whilst the pupil of one was under the influence of the Calabar bean. It consisted in the frequent and alteruate dilatation and contraction of the pupil, and appeared to be quite independent of any modification of the access of light or of movement of the eyeball. This lasted for at least ten minutes; and, it may be, for a longer period.

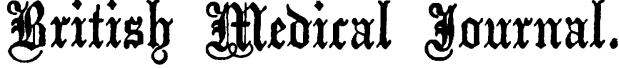

SATURDAY, JUNE 27тH, 1863.

\section{THE COLLEGE OF SURGEONS : ELECTION OF COUNCILLORS.}

A correspondent suggests to us that we were unjust to the Council of the Royal College of Surgeons of England, in saying that they had never fulfilled the terms of their new Charter. He reminds us that in onc particular, at all events, they have been most faithful to their charge. As we mentioned last week, a clause-a sop-was introduced into the Charter in order to make it more palatable to the ancients of the College, or, as our French friends would say, to the satisfaits de la vielle. Under this clause, the men then in office were permitted to hold it for life-that is, never to relinquish, as long as they lived, the $£ 300$ or $£ 400$-or whatever number of hundreds of pounds sterling it is that attaches to the performance of the pleasant, or at all events lucrative functions of College examiner.

Now, this clause the original men in office have most faithfully obeyed-with the one single exception, last week referred to, of Sir Benjamin Brodie. It may be interesting to record here who the original holders of office were-that is, in 1843. They were, Mr. Andrews, Sir B. C. Brodie, Mr. Samuel Cooper, Mr. H. L. Thomas, Mr. Keate, Mr. Vincent, Mr. Guthrie, Mr. A. White, Mr. Copeland, Mr. Briggs, Mr. Lawrence, Mr. Travers, Mr. Swan, Mr. Stanley, Mr. Green, Mr. Callaway, Mr. Babington, Mr. Liston, Mr. Arnott, Mr. South, and Mr. Morgan. of these, all but five have disappeared from the scene ; and, we may add, all died in College official harness. The five survivors of this famous Council are, Messrs. Lawrence, Swan, Green, Arnott, and South; and they are still Councillors, and four of them Examiners.

Sir Benjamin Brodie-the exceptional-disturbed by his action the even tenour of official holding which these "Antients" had struck out for themselves; he thought that the Charter's spirit should be carried out; and he paid the forfeit of his disobedience to their code of tenure of place. He was never made President of the College after that act. His crime was unpardonable. Those who stuck to office in spite of the Charter were made presidents two and three times; but Sir Benjamin Brodie, who vacated office according to the Charter, thereby showed that he was unworthy to occupy a second time the presidency of the College.*

* Under this head, we may refer to the very words of the Charter of 1832. We there read: "That the President and Vice-Presidents of the said Oollege shall no longer be chosen from or out of the Examiners of the said College, but from and out of all the members 673 